\title{
Percepções de Estudantes acerca de um Instrumento Diferenciado de Avaliação em Aulas de Matemática
}

\author{
Students Perceptions about a Differential Assessment Tool in Mathematics \\ Classroom
}

\author{
André Luis Trevisan* \\ Regina Luzia Corio de Buriasco **
}

\begin{abstract}
Resumo
O presente estudo descreve a percepção de estudantes do Ensino Médio acerca da utilização de um instrumento de avaliação diferenciado em aulas de Matemática: uma prova realizada em várias fases. Buscou-se identificar indícios de como viram e julgaram o instrumento (suas percepções), bem como identificar possíveis implicações de sua utilização sobre as estratégias de estudo desses estudantes. Para tal, foram analisados dados coletados por meio de um questionário respondido ao final da última fase da prova, bem como apontamentos por eles realizados em seus diários de aulas. As reflexões propiciadas a partir dessa análise possibilitaram compreender os próprios estudantes como sujeitos do processo de avaliação e permitiram analisar criticamente tanto o instrumento quanto a prática avaliativa do professor.
\end{abstract}

Palavras-chave: Educação Matemática. Avaliação da Aprendizagem Escolar. Prova em Fases. Percepções dos Estudantes.

\begin{abstract}
This study describes the perception of high school students about the use of a different assessment tool in Mathematics classes: a test carried out in several phases. We tried to identify evidence of how they saw and judged this instrument (their perceptions) and identify possible implications of this use on the student's study strategies. The data were analyzed and collected through a questionnaire answered by the students at the end of the last stage of the test, as well as notes performed by them in their daily lessons. The reflections afforded from this analysis helped us understand the students themselves as subjects of the assessment process and allowed a critical analysis of the instrument as well as of the teacher's assessment practice.
\end{abstract}

Keywords: Mathematics Education. Assessment in School Mathematics. Stage Test. Students Perceptions.

\section{Introdução}

\footnotetext{
"Doutor em Ensino de Ciências e Educação Matemática pela Universidade Estadual de Londrina (UEL). Docente da Universidade Tecnológica Federal do Paraná (UTFPR), Londrina, Paraná, Brasil. Endereço para correspondência: Av. Brasília, 2051, Cond. Portal das Flores, Jardim Alto da Boa Vista, CEP: 86600 - 224, Rolândia, Paraná, Brasil. E-mail: andrelt@utfpr.edu.br.

** Doutora em Educação pela Universidade Estadual Paulista (UNESP). Docente do Departamento de Matemática e do Programa de Pós-Graduação em Ensino de Ciências e Educação Matemática da Universidade Estadual de Londrina (UEL), Londrina, Paraná, Brasil. Endereço para correspondência: Rua Eduardo Benjamin Hosken, 173, apto 501, Centro, CEP 86020-440, Londrina, Paraná, Brasil. E-mail: reginaburiasco@ gmail.com.
} 
Tradicionalmente, as práticas avaliativas no contexto escolar limitam-se à utilização de alguns poucos instrumentos (senão um único - a prova escrita). Em geral, concentram-se na utilização de procedimentos de avaliação somativa, exercidos ao fim de um determinado período de tempo. Segundo Garcia (2009, p. 205), a manutenção dessa "antiga e persistente cultura avaliativa que tende a destacar particularmente a utilização de provas escritas ${ }^{1}$ para avaliar o grau de aprendizagem dos estudantes", acaba por limitar a percepção ${ }^{2}$ dos professores quanto à variedade de instrumentos que podem ser envolvidos na avaliação. Não só dos professores, mas também dos estudantes.

Esse autor lembra, ainda, que as práticas avaliativas exercidas pelos professores apresentam implicações no desenvolvimento cognitivo dos estudantes, ampliando ou limitando as oportunidades para que demonstrem o que aprenderam. Por um lado, suas “expectativas em relação às estratégias avaliativas utilizadas pelos professores determinam o modo como eles lidam com as tarefas acadêmicas e se preparam para as atividades de avaliação"; por outro, "experiências de avaliação proporcionadas aos estudantes influenciam suas atitudes", estratégias de estudo e abordagem de aprendizagem (GARCIA, 2009, p. 206).

[...] é a percepção dos estudantes sobre os elementos do ambiente de aprendizagem que determina como eles aprendem, e não necessariamente o contexto educacional em si. [...]. Isso parece sugerir a necessidade de os professores, na educação superior, estarem atentos ao modo como os alunos percebem suas práticas avaliativas (GARCIA, 2009, p.209).

Embora as considerações de Garcia (2009) refiram-se ao ensino superior, entendemos que elas se apliquem a todos os níveis de ensino. Assim, ao fazerem determinada opção para avaliar, os professores

[...] projetam expectativas e desenham um quadro a ser interpretado pelos estudantes. Tal interpretação reflete-se no modo de agir dos estudantes em sala de aula - como diferenciam conteúdos do currículo e desenvolvem hábitos de estudo e, de modo mais amplo, na aprendizagem, que exerce papel considerável em suas formações (GARCIA, 2009, p. 211).

Acerca do papel da avaliação no contexto escolar, Van Den Heuvel-Panhuizen (1996) aponta-a como parte integrante e indissociável do processo de ensino, sendo que a própria educação deve ser vista como um processo permanente de avaliação. Nessa mesma direção, trabalhos já desenvolvidos no GEPEMA ${ }^{3}$ (BURIASCO, 1999, 2000, 2002; VIOLA DOS SANTOS, BURIASCO, CIANI, 2008; BURIASCO, FERREIRA, CIANI, 2009; MENDES, TREVISAN, BURIASCO, 2012; TREVISAN, 2013; MENDES, 2014), Grupo de Estudo e

\footnotetext{
${ }^{1}$ Entendemos, aqui, o termo prova escrita como aquela individual, aplicada com tempo limitado e em um único momento (provas usualmente utilizadas nas escolas). Referimo-nos a ela como prova em uma fase, como forma de diferenciá-la da modalidade que envolve duas ou mais fases, apresentada na sequência deste texto.

${ }^{2}$ Por percepção referimo-nos ao modo de ver e julgar algo.

${ }^{3}$ http://www.uel.br/grupo-estudo/gepema/
} 
Pesquisa em Educação Matemática e Avaliação, apontam a avaliação como instrumento de formação presente no processo educativo, tanto como meio de diagnóstico dos processos de ensino e de aprendizagem dos estudantes, quanto como instrumento de investigação da prática pedagógica do professor, na medida em que lhe possibilita interpretar, regular e mediar esses processos.

No que tange ao ensino e à avaliação em Matemática, identificamos o movimento conhecido como Educação Matemática Realística (RME, do inglês Realistic Mathematics Education) como uma abordagem que vai ao encontro dessa perspectiva. Em RME, a Matemática deve ser tomada como atividade própria do estudante, que mobiliza suas próprias estratégias e procedimentos para explorar situações. Com vistas a obter um panorama o mais completo possível dos processos de matematização dos estudantes, a avaliação deve envolver o uso de uma extensa variedade de instrumentos para a coleta das informações.

Apesar de suas potencialidades, De Lange $(1987,1999)$ e Van Den Heuvel-Panhuizen (1996, 2000, 2003, 2005) apontam que, na maioria dos casos, as questões propostas nas provas escritas de Matemática concentram-se, unicamente, em habilidades simples, ignorando situações que exigem o estabelecimento de conexões ou mesmo possibilitem a matematização, não fornecendo informações completas das estruturas de conhecimento dos estudantes. Para esses autores, é fundamental explorar as potencialidades desse instrumento, bem como buscar alternativas às suas formas tradicionais. Uma delas seria a chamada prova em duas fases.

Encontramos na literatura (DE LANGE, 1987, 1999) a prova em duas fases como um exemplo de instrumento de avaliação resolvido em dois momentos distintos (uma primeira etapa em sala de aula, com tempo limitado, e uma segunda fase, num tempo maior, em geral, a ser feita em casa), que oportuniza aos estudantes refletir a respeito de seu próprio trabalho (uma vez que é devolvida com sugestões e comentários do professor).

O contato inicial com as ideias da RME e com os trabalhos do GEPEMA inspiraram o primeiro autor deste texto, logo no início do seu curso de Doutorado, a engajar-se num processo de reflexão acerca do processo de avaliação que utilizava em suas aulas e a repensar suas próprias práticas avaliativas. Numa proposta inicialmente pensada como piloto, foi organizada, no primeiro semestre de 2010, uma prova escrita de Matemática para uma turma do segundo ano do Ensino Médio, matriculados numa instituição federal de ensino na qual ele atuava como docente. A intenção inicial era investigar em que medida esse instrumento, com design similar à prova em duas fases (porém, organizada para ser resolvida em seis fases, 
todas em sala de aula), oportunizaria aos estudantes tomar a avaliação como uma oportunidade de aprendizagem.

Para sua elaboração, foram selecionadas vinte e oito questões que contemplavam todo o conteúdo programado para o semestre (no caso, trigonometria), provenientes de livros didáticos, listas de exercícios e provas aplicadas em anos anteriores: questões usuais, que, possivelmente, muitos outros professores escolheriam para compor uma prova. Por tratar-se de uma proposta inicialmente tomada como piloto, as questões que compuseram a prova foram selecionadas buscando contemplar todos os conteúdos previstos para aquele semestre e incluíam (segundo a percepção dele naquele momento), diferentes níveis de complexidade (fácil, médio, difícil). Visto que não serão objetos de análise deste texto, optamos por não apresentá-las.

Os próprios estudantes deveriam reconhecer/escolher quais questões resolver em cada fase (mesmo porque contemplavam conteúdos que ainda seriam explorados em aula), podendo alterar as resoluções, nas etapas subsequentes, sempre que julgassem necessário. Até a sexta fase, todo o conteúdo necessário à resolução das questões teria sido trabalhado em sala.

A prova foi entregue no primeiro dia de aula e os estudantes tiveram um tempo de 25 minutos para trabalhar com ela. A proposta, naquele momento, não era necessariamente que os estudantes resolvessem questões, mas apenas tomassem nota do que seria a prova naquele semestre. Ao final desse tempo, devolveram-na, e assim se sucedeu nas outras cinco fases, distribuídas ao longo daquele semestre, porém num tempo maior (100 minutos). Ao final da terceira fase, ao lado de cada resolução, foi apresentado um questionamento (pergunta/indagação, apresentada por escrito, ao lado da resolução apresentada pelo estudante), independentemente de a solução estar correta ou não, que buscava instigar os estudantes a refletirem acerca das resoluções apresentadas até aquele momento. Esse foi o único feedback que tiveram de sua prova.

À medida que o semestre passava, e passavam também as fases da prova, havia, tanto por parte do professor quanto dos estudantes, uma sensação de que as coisas estavam dando errado. Para o professor, a expectativa era que, ao possibilitar aos estudantes alterar suas resoluções nas várias fases da prova, isso de fato se efetivaria. Os estudantes, porém, mostraram-se descontentes com a proposta, e não deram o retorno que o professor previra.

Não bastou, porém, olhar para a experiência com olhos de fracasso, nem sucumbir frente ao "imobilismo gerado pelo sentimento de um conhecimento insuficiente" (HADJI, 1994, p. 129). No cotidiano daquela sala de aula usual, foi possível identificar um contexto 
propício à realização de uma investigação de caráter qualitativo, a partir da análise sistemática de dados recolhidos ao longo da experiência. As reflexões propiciadas a partir da análise das percepções dos estudantes (foco deste artigo) e da análise de sua produção escrita em questões da prova foram elementos que possibilitaram enxergar esse episódio de avaliação como uma oportunidade de aprendizagem e como uma prática de investigação (não exatamente para os estudantes, mas para o próprio professor).

Aquela que seria apenas uma experiência piloto tornou-se, então, o objeto central da pesquisa de Doutorado do primeiro autor (TREVISAN, 2013), realizada sob orientação da segunda autora. Como lembram Borba e Araújo (2004, p.27), o processo de construção da pesquisa é, "na maioria das vezes, um longo caminho, cheio de idas e vindas, mudanças de rumos, retrocessos". Esse design da pesquisa foi sendo construído, assim, à medida que a própria pesquisa desenvolvia-se.

Na sequência deste texto, apresentamos alguma discussão acerca do papel da avaliação no contexto da aprendizagem escolar. As percepções dos estudantes frente a esse instrumento diferenciado de avaliação, bem como as possíveis implicações dessa sobre suas atitudes de aprendizagem, evidenciadas por meio de apontamentos feitos em diários de aulas e das respostas a um questionário aplicado ao fim da última fase da prova, são descritas em detalhes. Além de possibilitar compreender os próprios estudantes como sujeitos do processo de avaliação, essa etapa do processo de pesquisa trouxe elementos que permitiram analisar criticamente o instrumento, bem como a própria prática avaliativa do professor. Tais reflexões finalizam o artigo.

\section{A busca por interlocutores}

Em "seu sentido mais nobre, a avaliação deveria ser de fato um encontro com o aluno visando melhorar seu trabalho" (BARLOW, 2006, p.54). Em linhas gerais, podemos dizer que essa frase resume, em poucas palavras, aquela que deveria ser a função essencial da avaliação no âmbito escolar, perspectiva essa apresentada por diversos outros autores (DE LANGE, 1987, 1999; HADJI, 1994; VAN DEN HEUVEL-PANHUIZEN, 1996; PONTE et al., 1997; BURIASCO, 1999, 2000, 2002; ESTEBAN, 2001; BARLOW, 2006), e da qual compartilhamos.

Tornar a avaliação parte dos processos de ensino e de aprendizagem implica exercê-la ao longo de toda ação de formação, torná-la permanente, passar da meta de identificar se os estudantes adquiriram conhecimentos que lhes foram propostos para a meta de preparar, 
orientar e aperfeiçoar a ação tanto do estudante quanto do próprio professor. Torná-la, portanto, formativa.

Seu objetivo é

[...] contribuir para melhorar a aprendizagem em curso, informando o professor sobre as condições em que está a decorrer essa aprendizagem, e instruindo o aprendente sobre o seu próprio percurso, os seus êxitos e as suas dificuldades (HADJI, 1994, p. 63).

Opondo-se à avaliação certificadora, a avaliação formativa implica em trocas entre professor e um estudante ou um grupo de estudantes, que ocorrem não no término da formação, mas durante seu processo. Trata-se,

[...] para o avaliador, de ajudar seus interlocutores a resolver melhor sua tarefa,
fazendo um diagnóstico das dificuldades ou das estratégias em questão. [...] Tais
ações de avaliação têm como meta, visivelmente, ajudar e encorajar, e desenvolvem-
se em clima caloroso. A tal ponto que alguns hesitam em falar em avaliação nesse
caso. Porém, não se pode duvidar que essas trocas tenham uma incidência sobre os
progressos das aprendizagens, que é exatamente o papel da avaliação, quaisquer que
sejam suas modalidades. Uma última característica desse tipo de intervenção é sua
dimensão pedagógica. Cabe qualificá-la de avaliação formativa (BARLOW, 2006,
p. 111 , grifo do autor).

Falar em avaliação formativa implica focar a atenção, pelo menos, em dois destinatários: o professor e o estudante. Se essa não tem outro objetivo senão a de ajudar os estudantes a aperfeiçoar suas aptidões, de fato a avaliação "dirige-se fundamentalmente ao aluno, de forma direta ou indireta, e apenas nesta condição ela é formativa, isto é, coloca-se a serviço de seu desenvolvimento intelectual” (BARLOW, 2006, p. 151).

Ao discutir as diferentes funções e os diferentes propósitos a que serve a avaliação, destacam-se duas delas: i) fornecer informação aos envolvidos nos processos de ensino e aprendizagem e ii) possibilitar que sejam tomadas decisões com vistas a aprimorar esses processos. Além de informar o próprio estudante, o professor, os pais, a escola, a comunidade, a respeito do seu progresso nos diferentes domínios de aprendizagem (função de controle), os resultados de uma avaliação fornecem dados para ajudar o professor a avaliar seu próprio ensino (função pedagógica). Esse papel informativo pode auxiliar a tomada de decisões, em especial por parte do estudante e do professor, que envolverá tanto o ajustamento do modo de estudar, por parte do estudante, como o modo de organizar o ensino, por parte do professor.

Assim, ao organizar instrumentos de avaliação, devemos ter em mente que esses constituam fontes de informação tanto para o professor quanto para aos estudantes. Ao primeiro, devem fornecer dados significativos que dizem respeito às aptidões, preferências e dificuldades de cada estudante, constituindo uma base para orientar futuras atividades. Aos estudantes, devem fornecer informações que os ajudem na reflexão e autorregulação 
relativamente aos seus próprios processos de aprendizagem, bem como gerar novas oportunidades para que eles, estudantes, aprendam.

\section{0 que os estudantes têm a nos dizer?}

$\mathrm{Na}$ tentativa de buscar indícios que nos permitissem compreender como viam e julgavam a prova (o que estamos denominando como suas percepções), analisamos anotações por eles realizadas em seus diários de aula. Esse instrumento, cuja elaboração foi proposta em caráter opcional, consistiu em um veículo para que dialogassem consigo mesmos e também com o professor a respeito da disciplina, contemplando, além de aspectos emocionais e afetivos, exemplos ilustrando os conceitos trabalhados em sala de aula, acompanhados de explicações. Enquanto ferramenta de diálogo, o diário de aulas foi fundamental como registro de apontamentos dos estudantes a respeito da prova em fases. Vários deles registravam no diário suas opiniões, suas dúvidas, seus avanços e mesmo suas angústias acerca do instrumento de avaliação.

Com vistas a identificar possíveis implicações da prova em fases sobre suas estratégias de estudo, organizamos um questionário aplicado ao final da última fase da prova, composto com quatro perguntas (questões abertas) elaboradas no intuito de fornecer ao professor elementos para avaliar a proposta de trabalho que estava sendo adotada junto à turma ao longo do semestre. Antes de ser aplicado, foi apresentado aos membros do GEPEMA, que indicaram sugestões para que as questões se mostrassem claras e a linguagem adequada. Nossa intenção com esse procedimento foi melhorar a qualidade e atribuir validade ${ }^{4}$ ao instrumento. Foi respondido de forma escrita pelos 24 estudantes que cursavam a disciplina.

Tais perguntas objetivaram saber como os estudantes se preparavam para a prova, se buscavam questões similares àquelas da prova, se os questionamentos levantados pelo professor interferiram em seus processos de resolução das questões e quais foram os pontos positivos e os pontos negativos do modelo de prova adotado.

Para relatarmos o que entendemos, dividimos nossa análise em dois itens, os quais comentamos a seguir.

\subsection{O que os estudantes pensavam a respeito da prova em fases?}

\footnotetext{
${ }^{4}$ Por validade estamos entendendo a capacidade do instrumento em medir, de fato, o que se propõe a medir.
} 
No que diz respeito aos diários de aula, destacamos, deles, alguns trechos que, de algum modo, remetem-nos ao processo de avaliação. Utilizamos o código de identificação formado pela letra $\mathrm{E}$ (estudante) seguido de uma numeração com dois dígitos $(01,02, \ldots, 25)$ segundo a ordem com que os nomes dos estudantes apareciam no diário de classe da disciplina. Como a elaboração do diário foi proposta em caráter optativo, apenas alguns estudantes dispuseram-se a fazê-lo.

Organizamos esses trechos no Quadro 1, no qual mantivemos as grafias originais utilizadas pelos estudantes. Entendemos que alguns termos utilizados, embora estejam gramaticalmente incorretos, podem fornecer informações implícitas da opinião dos estudantes. Isso ocorre, por exemplo, quando um estudante diz que, com essa proposta de prova, seria muita coisa pra lembraaa... ${ }^{5}$.

\begin{tabular}{|c|c|c|}
\hline & Data & Trecho \\
\hline \multirow{4}{*}{ E1 } & $24 / 03$ & $\begin{array}{l}\text { bom ao início desta semana logo na terça feira tivemos prova de matematica, esta muito } \\
\text { melhor do geito que o professor esta fazendo agora,esse novo sistema de prova nos } \\
\text { ajuda mais.... }\end{array}$ \\
\hline & $26 / 03$ & $\begin{array}{l}\text { bom esse sistema de prova ajuda mais pois são para os dois bimestres..alem do mais } \\
\text { apos a } 1^{\circ} \text { correção se tem algum exercício errado podemos refazer e isso ajuda para não } \\
\text { ficarmos de recuperação. e também podemos mesmo antes da correção refazer as } \\
\text { questões! }\end{array}$ \\
\hline & $01 / 06$ & ah ja ia me esquecendo muitas pessoas não gostaram do sistemas de provas.... \\
\hline & $25 / 06$ & $\begin{array}{l}\text { Professor muitos não gostaram pois disseram que preferem o outro sistema de provas } \\
\text { pois as questões que o senhor lançou após a primeira correção e eu também falo que } \\
\text { confundiu e ajudou a um certo ponto pois ao mesmo tempo da para corrigirmos as } \\
\text { questões errada. }\end{array}$ \\
\hline E3 & $07 / 06$ & $\begin{array}{l}\text { ah professor essas coisas sao muito complicadas de agora, tipo dá uns resultados muito } \\
\text { estranhos e nao da pra saber se ta certo ou nao, e nao adianta ver se ta tudo certinho ou } \\
\text { nao pra nao dá erro porq pra mim ta sempre certinho, mas sempre tem erros =/ }\end{array}$ \\
\hline E8 & Sem data & $\begin{array}{l}\text { Adorei essa idéia do diário....mto criativo! Mais não gostei do que jeito que a prova será } \\
\text { aplicadaaa... Aparenta ser mais complicado...será muita coisa pra lembraaa... }\end{array}$ \\
\hline \multirow[t]{2}{*}{ E15 } & $16 / 03$ & $\begin{array}{l}\text { Então... no } 1^{\circ} \text { dia de aula, eu não estava presente, mas fiz a prova em um outro dia. } \\
\text { Ainda não sei se é uma boa ideia fazer a mesma prova durante o bimestre. Por um lado } \\
\text { é bom, pois já da pra sabe o que tem que estuda para a próxima prova. Por outro lado é } \\
\text { ruim... pois quando eu fico muito tempo pensando em alguma coisa, nunca da certo! } \\
\text { Começo a refaze, a tenta fazer de outra forma., a imagina coisas.. e no final fica aquele } \\
\text { monte de coisa, e eu sem sabe qual é o certo! E isso em matemática é muito ruim.. =/ }\end{array}$ \\
\hline & $10 / 06$ & $\begin{array}{l}\text { Estou quase terminando a prova.. acho que falta apenas um } 5 \text { exercicios, mas tbm acho } \\
\text { q tem bastante incompleto, pq eu não mechi nos exercicios que eu ja tinha resolvido! } \\
\text { Isso não é bom.. mas como temos apenas mais um dia de prova, provavelmente não vai } \\
\text { da pra conferi e vê o que falta. Tomare que eu esteje indo bem.. apesar que eu acho que } \\
\text { não! A prova, na minha opiniao não esta dando certo! Ninguem gostou! }\end{array}$ \\
\hline E20 & $27 / 03$ & $\begin{array}{l}\text { a na prova tinha muitas coisas q a genet nao aprendeu ainda, mais o resto eu consegui } \\
\text { fzr.. }\end{array}$ \\
\hline \multirow[b]{2}{*}{ E22 } & $16 / 03$ & $\begin{array}{l}\text { O novo sistema se avaliação achei meio esquisito, não gostei. Mas vamos } \\
\text { experimentar. }\end{array}$ \\
\hline & $23 / 03$ & $\begin{array}{l}\text { A prova, tava meio misturado demais da conta, por isso perdi mnto tempo até achar os } \\
\text { exercícios. Resolvi três, talvez seja uma média não ruim, mas péssima. Tive um pouco } \\
\text { de dificuldade de interpretar alguns problemas, mas espero que da próxima vez dê mais } \\
\text { certo, mas tomara que as três que fiz tenha acertado. }\end{array}$ \\
\hline
\end{tabular}

5 As expressões em itálico, desta parte do texto em diante, explicitam transcrições de trechos das respostas/comentários apresentados pelos estudantes. 


\begin{tabular}{|l|l|l|}
\hline \multirow{2}{*}{$23 / 04$} & $\begin{array}{l}\text { Qd entreguei a prova, vc me perguntou se havia progredido. Essa progressão foi meio } \\
\text { stranha. De no mínimo } 8 \text { questões que vc disse pra com a outra somatória atingir os 70, } \\
\text { fiz } 7 \text { questões e metade de outra. Acho e tenho certeza que vou ficar com nota } \\
\text { vermelha, e isso me assusta, e dá um medo. (aff) }\end{array}$ \\
\cline { 2 - 3 } & $\begin{array}{l}\text { Oi professor, voltei!! Queria ser bem sincera quanto ao meu desempenho esse semestre, } \\
\text { um zero à esquerda. Aprendo as coisas na sala, chega na hora da prova não consigo } \\
\text { fazer nada. Tem coisas que não aprendi de jeito nenhum. Por favor professor, se tiver } \\
\text { como no próximo semestre volte para o sistema de antes, era mnto melhor. Se possível, } \\
\text { e se não for pedir mnto, dê um trabalho pra quem ficar com nota vermelha nos dois } \\
\text { bimestres para recuperar pelo menos um pouco }\end{array}$ \\
\hline E25 & $\begin{array}{l}\text { A prova foi de boa na lagoa, tirando um exercício de trigonometria que eu sabia que } \\
\text { dava pra resolver e não resolvi porque não sabia por onde começar. }\end{array}$ \\
\hline
\end{tabular}

Quadro 1 - Trechos dos diários de aula que remetem ao processo de avaliação. Fonte: elaborado pelos autores.

Analisemos os dados apresentados. Suas falas evidenciam reações de expectativa (espero que da próxima vez dê mais certo, dá uns resultados muito estranhos e não da pra saber se tá certo ou não), desafio (não gostei. Mas vamos experimentar) e mesmo fatalismo (no final fica aquele monte de coisa, e eu sem sabe qual é o certo, foi horrível, não deu certo).

O motivo da insatisfação de alguns estudantes com esse modelo de prova não estava claro para muitos deles: a prova confunde muito, ou o negativo eu não sei, mas prefiro provas comuns. A última fala explicita que, perante os estudantes, esse instrumento de avaliação é bastante incomum: o usual são várias provas ocorrendo ao fim de curtos períodos de tempo, com lista de conteúdos delimitada, e com questões similares àquelas propostas em aula. De fato, este é o modelo de prova que havia sido adotado na disciplina de Matemática no ano anterior, e que a quase totalidade dos professores utilizou em outras disciplinas.

Ao dizer que achava estranho estudar para uma prova que já conhecia, esse estudante estaria, implicitamente, nos levando a pensar que uma prova deveria ser "imprevisível para ser eficaz", como acredita o professor Roger Ikor (BARLOW, 2006, p. 68)? O rito do controle escolar cai por terra quando propomos que o estudante conheça de antemão a prova. Foi inesquecível a imagem dos seus semblantes ao recebê-la no primeiro dia de aula. Os próprios estudantes mostraram-se perdidos: como agir frente a essa facilitação propiciada pelo professor? Como se poderia trapacear o professor; afinal "elaboram-se no imaginário escolar ritos e mitos que glorificam a trapaça" (BARLOW, 2006, p. 113)? Afinal, "o ritual do controle escolar [...] parece fundamentar-se no princípio de que todos os alunos são trapaceiros em potencial".

Conforme apontou Garcia (2009), as concepções de aprendizagem dos estudantes relacionam-se aos contextos educacionais a que são expostos, o que inclui, igualmente, as práticas de avaliação. Assim, entendemos que o conhecer as questões da prova pode ser uma oportunidade para que o estudante mobilize suas próprias estratégias e procedimentos na 
busca de explorá-las (como pressupõe a RME), priorizando sua autonomia e aproximando-o de uma aprendizagem autêntica.

Um fato que chamou bastante a atenção diz respeito aos questionamentos feitos acerca da recuperação. O que seria recuperação, senão propor um instrumento que possibilitasse ao estudante repensar as questões, voltar atrás, superar suas dificuldades, enfim, autorregular sua aprendizagem (HADJI, 1994)? Isso era o que o professor pensava, não os estudantes. O rito das duas provas bimestrais, mais uma prova de recuperação na última semana de aula do bimestre era o que eles conheciam e esperavam. Para eles, recuperação era sinônimo de resolver outra prova (prova de recuperação), composta por questões similares àquelas que compuseram provas aplicadas ao longo do bimestre. Para que ficar inventando moda então, como disseram (e continuaram dizendo em conversas de corredor no ano seguinte)? O que você vai inventar agora? foi um questionamento recorrente e presente já no primeiro dia de aula no ano seguinte.

Para vários estudantes, porém, a proposta de utilização de um instrumento diferenciado de avaliação foi avaliada positivamente: esse novo sistema de prova nos ajuda mais, pra saber o que tem que estudar para a próxima prova, a prova foi de boa na lagoa ${ }^{6}$. Há indícios, portanto, de que para esses estudantes a proposta de avaliação tenha contribuído na direção de autorregularem seus próprios processos de aprendizagem, bem como gerado novas oportunidades para eles aprenderem.

\subsection{A prova em fases: implicações nas estratégias de estudo dos estudantes}

A tabulação dos dados referentes ao questionário deu origem às Tabelas 1 a 3, com as quais apresentamos a análise.

No que diz respeito à primeira pergunta do questionário (Tabela 1), Como você se preparava para cada uma das etapas da prova?, cinco estudantes disseram revisar tarefas feitas em aula, ou buscar resolver outras. Outros cinco estudantes disseram procurar questões parecidas com aquelas da prova, no livro didático usado em aula, em outros livros didáticos e na internet, sendo que um deles disse, entretanto, não saber como resolvê-las (procurava, mas sem saber o que fazer). Dez estudantes disseram preparar-se para a prova revisando o conteúdo, a maioria sem explicitar como essa revisão era feita. Desses, dois informaram revisar apenas o último assunto visto após cada fase da prova. Três estudantes disseram

\footnotetext{
${ }^{6}$ Expressão que remete à ideia de uma prova tranquila, sossegada.
} 
prestar atenção às aulas, e um deles enfatizou que, por esse motivo, não precisava estudar em casa. Por fim, um estudante informou que achava estranho estudar para uma prova que já conhecia, mas mesmo assim tentava se preparar, sem explicitar o modo como fazia isso.

Tabela 1 - Como os estudantes se preparavam para a prova em fases.

\begin{tabular}{lc}
\hline Respostas & Número de estudantes \\
\hline Revisar tarefas feitas em aula e/ou resolver outras. & 5 \\
Procurar questões parecidas com a da prova. & 5 \\
Revisar o conteúdo. & 10 \\
Prestar atenção às aulas. & 3 \\
Não explicitado & 1 \\
\hline
\end{tabular}

Fonte: elaborada pelos autores.

A segunda pergunta (Tabela 2) foi elaborada com o objetivo de evidenciar se, em sua rotina de estudos, buscavam temas ou questões similares àquelas que estavam na prova. Três deles disseram que não buscavam, e um informou que não o fazia porque esquecia as questões. Quatro disseram que às vezes procuravam questões similares, e entre eles, dois completaram que, quando faziam essa busca, era entre as questões discutidas em aula ou propostas nas tarefas que o professor passava.

Tabela 2 - Os estudantes procuravam questões similares às da prova?

\begin{tabular}{lc}
\hline Respostas & Número de estudantes \\
\hline Não & 3 \\
Às vezes & 4 \\
Sim & 17 \\
\hline \multicolumn{2}{c}{ Fonte: elaborada pelos autores. }
\end{tabular}

Os demais responderam que sim. Entretanto, em suas respostas, vários desses estudantes (10 deles, mais precisamente) pareciam ter lidado com as questões no intuito de memorizá-las, restringindo-se a buscar no livro ou caderno questões idênticas a elas. Esses estudantes parecem ter adotado uma estratégia muito mais focada na memorização e reprodução de aspectos factuais subjacentes às questões, na expectativa de, antes da próxima fase da prova, encontrarem a resolução de tais questões em algum material, como se fosse um lance de sorte. Para Garcia (2009, p.207-208), trata-se de uma abordagem de aprendizagem "de superfície", na qual os estudantes interagem com os conteúdos curriculares "para obter aquilo que lhes parece necessário aprender, tendo em vista determinada atividade ou forma de avaliação, mas sem a intenção de relacionar os conhecimentos estudados a uma perspectiva conceitual mais ampla".

Por outro lado, sete dos estudantes que afirmaram procurar questões similares às da prova durante seus estudos parecem aproximar-se de uma abordagem profunda de aprendizagem, segundo Garcia (2009), uma vez que pareciam dispender um esforço efetivo de análise e compreensão de conceitos e princípios subjacentes àquelas questões. 
$\mathrm{Na}$ terceira pergunta (Tabela 3): os questionamentos levantados pelo professor ao lado de suas resoluções contribuíram para o processo de resolução da prova? Por quê?, os estudantes mostraram-se bastante divididos. Dez disseram que não, apresentando diversos motivos: perdiam muito tempo buscando identificar se havia algo errado em suas resoluções, ou mesmo tentando responder aos questionamentos; alguns questionamentos eram sem nexo; não conseguiam identificar os erros por meio dos questionamentos; ficavam com mais dúvidas se sua resposta estava certa ou errada (e preferiam deixar a resolução como estava). Um dos estudantes informou que foi horrível, não deu certo e, para outro, é raro um aluno ter certeza do que fez em uma prova de matemática, e fica pior ainda quando nem um certo nem um errado está ao lado, e ainda tem perguntas. Para cinco estudantes, alguns questionamentos ajudavam, e outros não. Um deles disse que, apesar dos questionamentos o terem ajudado, alguns deles fizeram-no de bobo, já que a resolução originalmente apresentada estava correta. Por fim, para nove estudantes, os questionamentos feitos foram positivos, pois possibilitaram perceber algumas coisas que estavam erradas, ou porque se dava a chance de resolver de novo corrigindo o erro.

Tabela 3 - Os questionamentos contribuíram para a resolução da prova?

\begin{tabular}{lc}
\hline Respostas & Número de estudantes \\
\hline Não & 10 \\
Às vezes & 5 \\
Sim & 9 \\
\hline
\end{tabular}

Fonte: elaborada pelos autores.

$\mathrm{Na}$ quarta e última pergunta, foi pedido que apontassem pontos positivos e pontos negativos em relação ao modelo de prova que havia sido adotado ao longo daquele semestre.

Foram considerados pontos positivos a possibilidade oferecida por esse formato de prova do estudante:

- corrigir, nas etapas subsequentes, as resoluções apresentadas;

- buscar questões similares enquanto preparava-se para a prova;

- preparar-se para prova estudando exatamente o que cai na prova;

- reconhecer similaridade entre as questões da prova e aquelas que eram trabalhadas ao longo das aulas e também propostas nas tarefas.

Foram considerados pontos negativos nesse formato de prova:

- o acúmulo de conteúdos cobrados numa mesma prova;

- o pouco tempo para resolução dos exercícios;

- a dificuldade em identificar questões que já estariam aptos a resolver a cada fase;

- a ausência de indicação de certo ou errado nas questões; 
- a dificuldade em recordar tópicos que já tinham sido estudados havia algum tempo.

É interessante notar que, embora esse modelo de instrumento de avaliação possa desencadear nos estudantes a exploração de uma gama de habilidades cognitivas (na medida em que incentiva a autonomia e os encoraja a compreender mais profundamente conteúdos subjacentes às questões da prova - conhecidas de antemão), a tal aspecto não pareceu ter sido dada a relativa importância.

Trata-se de uma característica da avaliação formativa, que pressupõe, também, a existência de trocas entre professor e estudante, que ocorrem não no término da formação, mas durante seu processo (BARLOW, 2006). Entretanto, a ideia arraigada na prática escolar de que cabe ao professor ditar sobre o certo ou errado acabou por minimizar (ou mesmo anular) tais aspectos.

\section{Algumas considerações: um repensar da prática avaliativa}

A análise das percepções dos estudantes permitiu inferir que, embora o instrumento prova escrita tivesse se modificado, seu próprio design carregava uma visão tradicional de avaliação. O descrédito inicial com a utilização da prova em fases revelou mais que um descontentamento com o instrumento por si só, mas uma perspectiva de avaliação limitada a uma vertente puramente de rendimento. $\mathrm{O}$ aparente fracasso com a prova em fases, e a busca por razões que justificassem tal fracasso, levou o professor a repensar o modo como estava avaliando os estudantes.

Conforme apontou Garcia (2009), as experiências de avaliação são parte importante do currículo, podendo ser formativas sob diversos aspectos. Assim, se, por um lado, a experiência pontual de utilização da prova em fases na turma em tela não pode ser tomada como uma prática de avaliação formativa para os estudantes, foi inegável seu potencial formativo para o próprio professor.

A intenção inicial de esboçar um possível design para a prova em fases que oportunizasse aos estudantes tomar a avaliação como oportunidade de aprendizagem esbarrou na própria concepção de avaliação do professor. Afinal, como lembra Barlow (2006, p. 165), “a 'virtude' formativa não está no instrumento, mas sim, se assim se pode dizer, no uso que dele fazemos, na utilização das informações produzidas graças a ele”. Efetivamente, não se pode idealizar um modelo ideal de instrumento; porém, o exercício nessa direção contribuiu para vislumbrar o papel informativo que a avaliação pode trazer para o professor. 
Por que os estudantes, afinal, não compraram a ideia da prova em fases? Ora, a própria resistência ao novo pode ter sido uma das razões. Num modelo de escola calcado numa função certificadora de avaliação, os estudantes naturalmente acabam por ajustar-se àquela que se mostra como uma sequência natural das coisas: ao fim de uma sequência de ensino, o professor aplica uma prova que lhe permite verificar quais competências foram atingidas, informação essa quantificada por meio de uma nota, informada e selada como fim de uma etapa de trabalho.

A utilização da prova em fases colocou em xeque esse modelo de avaliação na qual os estudantes já estavam moldados. Antes de tudo, porque a prova já era conhecida. Assim como eles sentiam-se desconfortáveis com esse fato, pois não sabiam bem como estudar para uma prova que já conheciam, o professor acabava por orientar as aulas com vistas a prepará-los para resolver a prova.

Além disso, a possibilidade de fazer e refazer as questões da prova quantas vezes fossem necessárias, oportunidade genuína quando se fala em feedback num contexto de avaliação formativa, mostrou-se bastante limitada naquele momento. A releitura das questões da prova, propiciada por meio da análise da produção escrita dos estudantes, mostrou que os questionamentos apresentados ao lado de suas resoluções foram bastante limitados, e em pouco contribuíram na direção de possibilitar que reconhecessem e corrigissem seus erros. O aprimoramento da arte de fazer perguntas deve ser um exercício constante na prática do professor que busca tornar a avaliação uma oportunidade de aprendizagem aos seus estudantes.

Como resultado da tese da qual este artigo é recorte, destacamos que a adoção de uma atividade crítica, frente às próprias ações enquanto professor-avaliador, apontou mecanismos de desenvolvimento de habilidades necessárias à formação de sujeitos avaliadores, por meio da reflexão sobre a ação avaliativa. A análise da experiência, inicialmente suposta como fracasso, aos poucos foi percebida como fundamental na modificação da própria prática pedagógica. Nesse processo, a atitude passiva frente a uma avaliação em que se busca medir o quanto de uma técnica ou algoritmo é reproduzida pelo estudante foi, aos poucos, caindo por terra. A partir da análise das percepções dos estudantes, pudemos identificar três focos para análise: os itens que compuseram a prova, o conteúdo matemático subjacente a esses itens e as próprias atitudes enquanto professor de Matemática. $\mathrm{O}$ relatório de pesquisa como um todo foi, assim, sendo tecido, procurando contrapor criticamente o que foi feito com aquilo que poderia ter sido feito, numa tentativa constante de repensar a própria prática avaliativa. 


\section{Referências}

BARLOW, M. Avaliação escolar: mitos e realidades. Porto Alegre: Artmed, 2006.

BORBA, M. C.; ARAÚJO, J. L. (Orgs). Pesquisa Qualitativa em Educação Matemática. Belo Horizonte: Autêntica, 2004.

BURIASCO, R. L. C. Avaliação em Matemática: um estudo das respostas de alunos e professores. 1999. 238f. Tese (Doutorado em Educação) - Universidade Estadual Paulista, Marília, 1999. Disponível em: <http://www.uel.br/grupo-estudo/gepema/Disserta \%E7\%F5es/Tese\%20\%20Buriasco.pdf>. Acesso em: 21 set. 2013.

BURIASCO, R. L. C. de. Algumas considerações sobre avaliação educacional. Estudos em Avaliação Educacional, São Paulo, n. 22, p. 155-177, jul./dez. 2000. Disponível em: <http://www .fcc.org.br/pesquisa/publicacoes/eae/arquivos/1001/1001.pdf>. Acesso em: 21 set. 2013.

BURIASCO, R. L. C. de. Sobre Avaliação em Matemática: uma reflexão. Educação em Revista, Belo Horizonte, n. 36, p. 255-263, 2002.

BURIASCO, R. L. C.; FERREIRA, P. E. A.; CIANI, A. B. Avaliação como Prática de Investigação (alguns apontamentos). Bolema- Boletim de Educação Matemática, Rio Claro, v. 22, p. 69-96, 2009. Disponível em: 〈http://www2.rc.unesp.br/bolema/?q=node/227>. Acesso em: 02 out. 2013.

DE LANGE, J. Mathematics, Insight and Meaning. Utrecht: OW \&OC, 1987.

DE LANGE, J. Framework for classroom assessment in mathematics. Utrecht: Freudenthal Institute and National Center for Improving Student Learning and Achievement in Mathematics and Science, 1999. Disponível em: <http://www.fi.uu.nl/publicaties/literatuur/6279.pdf>. Acesso em: 12 jun. 2010.

ESTEBAN, M. T. Avaliar: ato tecido pelas imprecisões do cotidiano. In: GARCIA, R. L. (Org.). Novos olhares sobre a alfabetização. São Paulo: Cortez, 2001. p. 175-192. Disponível em: <http://www.anped.org.br/reunioes/23/textos/ 0611t.pdf >. Acesso em: 15 jun. 2010.

GARCIA, J Avaliação e aprendizagem na educação superior. Estudos em Avaliação Educacional, São Paulo, v. 20, n. 43, p. 201-213, mai./ago. 2009. Disponível em: 〈http://www.fcc.org.br/pesquisa/publicacoes/eae/arquivos/1494/1494.pdf >. Acesso em: 21 set. 2013.

HADJI, C. A avaliação, regras do jogo. 4. ed. Portugal: Porto, 1994.

MENDES, M. T. Utilização da Prova em fases como recurso para aprendizagem em aulas de Cálculo. 2014. 275f. Tese (Doutorado em Ensino de Ciências e Educação Matemática) - Universidade Estadual de Londrina, Londrina, 2014. Disponível em: <http://www .uel.br/pos/mecem/arquivos_pdf/2014_tese_Marcele.pdf $>$. Acesso em: 04 set. 2014.

MENDES, M. T.; TREVISAN, A. L.; BURIASCO, R. L. C. Possibilidades de Intervenção num Contexto de Ensino e Avaliação em Matemática. EM TEIA - Revista de Educação Matemática e Tecnológica Iberoamericana, Recife/PE, v. 3, p. 1-13, 2012. Disponível em: <http://www.gente.eti.br/revistas/index.php/emteia/article/view/86>. Acesso em: 12 mar. 2013.

PONTE, J. P. et al. Didática da Matemática: ensino secundário. Lisboa: Ministério da Educação/Departamento do ensino secundário, 1997. 134 p. Disponível em: <www.dgidc.minedu.pt/outrosprojetos/data/outrosprojectos/Matematica/ Documentos/Brochuras Secundario/ didactica completa.pdf>. Acesso em: 12 mai. 2011. 
TREVISAN, A.L. Prova em fases e um repensar da prática avaliativa em Matemática. 2013. 168 f. Tese (Doutorado em Ensino de Ciências e Educação Matemática) - Universidade Estadual de Londrina, Londrina, 2013. Disponível em: <http://www.uel.br/pos/mecem/arquivos_pdf/ TREVISAN_Andre tese.pdf $>$. Acesso em: 21 set. 2013.

VAN DEN HEUVEL-PANHUIZEN, M. V. D. Assessment and Realistic Mathematics Education. Utrecht: CD-ß Press/Freudenthal Institute, Utrecht University. 1996. Disponível em: <http://www.sta ff.science.uu.nl/ heuve108/download/ICME\%2012\%20Regular\%20Lecture/vdHeuvel_1996_assess ment-and-RME.pdf > . Acesso em: 21 set. 2013.

VAN DEN HEUVEL-PANHUIZEN, M. V. D. Mathematics education in the Netherlands: a guided tour. Utrecht: Freudenthal Institute Cd-rom for ICME9, Utrecht University, 2000. Disponível em: <http://www.fisme.science.uu.nl/staff/marjah/ documents/TOURdef+ref.pdf $>$. Acesso em: $01 \mathrm{abr}$. 2015 .

VAN DEN HEUVEL-PANHUIZEN, M. V. D. The didactical use of models in realistic mathematics education: an example from a longitudinal trajectory on percentage. Educational Studies in Mathematics, Netherlands, v. 54, n. 1, p. 09-35, 2003. Disponível em:

<http://www.fi.uu.nl/publicaties/literatuur/2003_heuvel_panhuizen_model.pdf $>$. Acesso em: 01 abr. 2015.

VAN DEN HEUVEL-PANHUIZEN, M. V. D. The role of contexts in assessment problems in mathematics. For the Learning Mathematics, Alberta/Canadá, v. 25, n. 2, p. 2-9, 2005. Disponível em: 〈http://www.fisme.science.uu.nl/staff/marjah/documents/01-Heuvel.pdf $>$. Acesso em: $01 \mathrm{abr}$. 2015 .

SANTOS, J. R. V. dos ; BURIASCO, R. L. C. de; CIANI, A. B. A avaliação como prática de investigação e análise da produção escrita em matemática. Revista de Educação, Campinas, v. 13, p. 35-45, 2008. Disponível em: <http://periodicos.puc-campinas.edu.br/ seer/index.php/reveducacao/article/view/106/94> . Acesso em: 21 set. 2013. 